\title{
Substituição parcial de silagem de milho por farelo de glúten de milho desidratado na alimentação de vacas holandesas em lactação
}

\author{
Ana Carolina do Nascimento Alves ${ }^{1}$, Wilson Roberto Soares Mattos ${ }^{2}$, Flávio Augusto Portela \\ Santos ${ }^{2}$, Maria Lúcia Pereira Lima ${ }^{3}$, Claudia Cristina Paro de $\mathrm{Paz}^{3}$, Alexandre Mendonça \\ Pedroso 4
}

\footnotetext{
${ }^{1}$ Mestranda do Departamento de Zootecnia da ESALQ/USP. Av. Bandeirantes, 2419, CEP: 14030-670, Ribeirão Preto, SP.

${ }^{2}$ Departamento de Zootecnia da ESALQ/USP. C.P. 9 CEP: 13418-900, Piracicaba, SP.

3 APTA/SAA-SP, Av. Bandeirantes, 2419. CEP: 14030-670, Ribeirão Preto, SP.

${ }^{4}$ Doutorando do Departamento de Zootecnia da ESALQ/USP. C.P. 9. CEP: 13418-900, Piracicaba, SP.
}

RESUMO - Objetivou-se estudar o efeito da substituição de parte da silagem de milho por farelo de glúten de milho (FGM-21) desidratado na produção e composição do leite e nos parâmetros sangüíneos de vacas em lactação e avaliar economicamente essa substituição. Foram avaliados os níveis 0,8 e 16\% de inclusão de FGM-21 (\% MS) nas dietas. Trinta vacas foram utilizadas no estudo da produção e composição do leite e 15 vacas no estudo dos parâmetros sangüíneos. O delineamento experimental foi quadrado latino $3 \times 3 \mathrm{com}$ dez replicações. Houve diferença entre as dietas para a produção de leite e a produção de leite corrigida para 3,5\% de gordura. As demais características estudadas não diferiram entre as dietas. Para produção de leite, foram obtidos os valores de 22,44; 23,69 e 23,88 kg/vaca/dia; para produção de leite corrigida para 3,5\% de gordura, 23,25; 24,71 e 24,44 kg/vaca/dia; para porcentagem de gordura, 3,69; 3,76 e 3,65\%; para proteína no leite, 3,22; 3,20 e 3,25\%; lactose, 4,29; 4,32 e 4,31\%; sólidos totais, 12,$12 ; 12,23$ e 12,14\%; N-uréico no leite, 16,57; 16,50 e 14,96 mg/dL; N-uréico plasmático, 19,92; 21,17 e 20,21 mg/dL; e para glicose sérica, 55,69;56,50 e 54,78 mg/dL nos níveis 0 , 8 e 16\% de FGM-21, respectivamente. A dieta com 16\% de FGM-21 resultou em maior lucro.

Palavras-chave: composição de leite, farelo de glúten de milho, silagem de milho, subproduto

\section{Partial replacement of corn silage by corn gluten feed in the feeding of dairy Holstein cows in lactation}

\begin{abstract}
The objective was to study the effects of partial replacing of corn silage by corn gluten feed (CGF-21) dehydrated on milk production and composition of milk and in the blood parameters of dairy cows, beyond the economic evaluation. Inclusion levels of 0,8 and $16 \%$ of CGF-21 (\% DM) to the diets were evaluated. Thirty cows were used for study of milk production and composition and fifteen cows for blood parameters study. A 3 x 3 Latin Square experimental design with ten replications was used. There was difference among diets for milk yield and for $3.5 \%$ fat correct milk. No difference among diets was observed for the other studied characteristics. The results obtained for milk yield were: $22.44,23.69$ and $23.88 \mathrm{~kg} / \mathrm{anim} . \mathrm{d}$ and for $3.5 \%$ fat correct milk were: $23.25,24.71$ and $24.44 \mathrm{~kg} / \mathrm{anim}$.d, respectively, for the inclusionj levels of CGF-21 for the inclusion levels of 0,8 and $16 \%$ of CGF-21 in the diet. The results obtained for the composition of milk were: percentage of fat, 3.69, 3.76 and 3.65\%; milk protein, 3.22; 3.20 and $3.25 \%$; lactose, 4.29, 4.32 and 4.31\%; total solids, 12.12, 12.23 and 12.14\%; N-ureic milk, 16.57, 16.50 and $14.96 \mathrm{mg} / \mathrm{dL}$, and for blood parameters were: plasma $\mathrm{N}$ ureic, $109.92,21.17$ and $20.21 \mathrm{mg} / \mathrm{dL}$, seric glucose, $55.69,56.50$ and $54.78 \mathrm{mg} / \mathrm{dL}$, respectively, for the inclusion levels of 0,8 and $16 \%$ of CGF-21 in the diet. The diet with the inclusion of $16 \%$ of CGF-21 result on a greater profit.
\end{abstract}

Key Words: by-products, corn gluten feed, corn silage, milk composition

\section{Introdução}

A utilização de subprodutos é uma alternativa na alimentação do gado leiteiro, por apresentar duas grandes vantagens, a diminuição da dependência dos bovinos por cereais utilizados na alimentação humana e a diminuição no custo total de produção. Para ser economicamente atrativo, o subproduto deve ter baixo custo por unidade de MS (Imaizumi, 2005).

Na América Latina, são produzidos mais de 500 milhões de toneladas de subprodutos e resíduos agroindustriais. O Brasil produz mais da metade e, apesar de serem pobres em 
nutrientes, esses subprodutos podem suprir, em parte, as necessidades energéticas dos animais, pois geralmente são abundantes em fibra e ricos em lignina e sílica (Souza \& Santos, 2004).

As variedades dos alimentos utilizados na alimentação de ruminantes são numerosas e seu valor nutricional é determinado por uma complexa interação entre seus constituintes com os microrganismos do trato digestivo nos processos de digestão, absorção e transporte e na utilização de metabólitos, além da própria condição fisiológica do animal. Para que o ruminante expresse seu potencial genético máximo, é importante o fornecimento de níveis adequados de nutrientes por meio de dieta balanceada (Dutra et al., 1997).

Normalmente, subprodutos da agroindústria são utilizados para substituir os concentrados, no entanto, resíduos como o farelo de glúten de milho (FGM-21) podem ser adequados para substituir volumosos. Esse subproduto, cuja fonte de fibra apresenta boa digestibilidade em ruminantes, pode ocasionar redução no teor de amido das dietas e concomitante aumento nos teores de fibra digestível, contribuindo para melhoria do ambiente ruminal (Grant, 2005).

O FGM-21, resíduo proveniente do processamento do milho na fabricação de amido de milho e de adoçante, apresenta aproximadamente $21 \%$ de PB, $83 \%$ de NDT, $45 \%$ de FDN e $36 \%$ de FDN efetiva (NRC, 2001). Esse subproduto pode ser uma alternativa interessante para substituir, em parte, a silagem de milho de dietas para vacas em lactação.

Reis et al. (1995) forneceram promil-21 (nome comercial de um dos produtos FGM-21) a ovinos e verificaram aumento da digestibilidade da hemicelulose da palha de aveia tratada com amônia em dietas com $32 \%$ da MS deste subproduto.

Em geral, a silagem de milho é um volumoso muito utilizado em propriedades leiteiras e pode representar $40 \mathrm{a}$ $50 \%$ da MS em dietas para vacas de alta produção. Todavia, seu custo de produção pode limitar seu uso por grande número de produtores. A intensificação nos sistemas de produção animal tem aumentado o risco de transtornos metabólicos nos rebanhos leiteiros, uma vez que o desafio metabólico imposto pela maior produtividade favorece o desequilíbrio entre o aporte de nutrientes no organismo, a capacidade de metabolismo desses componentes e os níveis de produção alcançados (González, 2000).

Durante várias décadas, a análise dos componentes sangüíneos tem sido a forma mais freqüente de se conhecer e interpretar o estado de saúde da vaca leiteira, principalmente seu estado metabólico (Wittwer, 1993). Assim, os níveis séricos de uréia e glicose permitem estabelecer o equilíbrio nutricional o grau de adequação das dietas aos animais, além dos diagnósticos de doenças metabólicas e da funcionalidade de órgãos vitais para produção de leite.

Objetivou-se neste estudo avaliar os efeitos da substituição de parte da silagem de milho por FGM-21 desidratado em dietas para vacas holandesas em lactação sobre a produção e a composição do leite, os parâmetros sanguíneos metabólicos e a viabilidade econômica das dietas.

\section{Material e Métodos}

O experimento foi conduzido em instalações do tipo free stall do Departamento de Zootecnia da Escola Superior de Agricultura Luiz de Queiroz, da Universidade de São Paulo, em Piracicaba, São Paulo.

Foram utilizadas 30 vacas Holandesas com produção de leite de 25 a $30 \mathrm{~kg} /$ dia e com período médio de lactação de 150 dias para determinação da composição e produção de leite. Para determinação dos parâmetros metabólicos, foram utilizadas 15 vacas Holandesas, pertencentes ao mesmo grupo, com produção de leite média de 30 a $35 \mathrm{~kg} /$ dia.

O delineamento estatístico utilizado foi o quadrado latino $3 \times 3$ com dez repetições. As análises estatísticas foram feitas pelo procedimento GLM (SAS, 2003) e, para a comparação entre as médias, utilizaram-se os contrastes linear (L) e quadrático (Q). À exceção das demais variáveis, o consumo de MS e a avaliação econômica não foram analisados estatisticamente. O modelo utilizado na análise foi:

$$
\mathrm{y}=\mu+\mathrm{P}+\mathrm{Q}+\mathrm{A}(\mathrm{Q})+\mathrm{T}+\mathrm{D}+\mathrm{e}
$$

em que: $y=$ produção de leite, composição do leite, variação de peso, escore de condição corporal; $\mu=$ média geral; $\mathrm{P}=$ efeito do período; $\mathrm{Q}=$ efeito do quadrado; $\mathrm{A}(\mathrm{Q})=$ efeito do animal aninhado dentro do quadrado; $\mathrm{T}=$ efeito do tratamento; $\mathrm{D}=$ efeito do dia; e = efeito residual aleatório.

Os animais foram alimentados duas vezes ao dia, às 6 e $17 \mathrm{~h}$ e as sobras de alimento foram pesadas e descartadas diariamente para estimativa do consumo de MS no grupo de vacas de cada dieta. A silagem de milho e o FGM-21 foram amostrados semanalmente e os outros alimentos, no início de cada período experimental, para formação de uma única amostra composta de cada dieta, para posterior análise bromatológica, realizada segundo AOAC (1990) e Harris (1970). Os teores de FDN e FDA foram analisados segundo Van Soest et al. (1991). Os carboidratos não-fibrosos (CNF) foram calculados pela fórmula: $\mathrm{CNF}=100-(\mathrm{PB}+\mathrm{FDN}+$ cinzas $+\mathrm{EE})$.

Os animais foram pesados e seus escores de condição corporal (ECC) foram avaliados no início do experimento e 
ao final de cada período experimental, segundo metodologia descrita por Wildman et al. (1982). A média de peso das vacas foi de $648 \mathrm{~kg}$ e o escore corporal, de 2,8 .

Foram fornecidas três dietas experimentais para comparação dos três níveis de farelo de glúten de milho $(0,8$ e $16 \%$ da MS) em substituição à silagem de milho. As dietas foram formuladas conforme descrito pelo NRC (2001) para serem isoprotéicas (Tabelas 1, 2 e 3).

O experimento teve duração de 60 dias e foi dividido em três períodos de 20 dias, os 17 primeiros para adaptação dos animais às dietas e os três últimos para coleta de dados, segundo metodologia descrita por Santos et al. (2006).

Tabela 1 - Composição das dietas experimentais, em \% MS Table 1 - Composition of the experimental diets, \% of DM

\begin{tabular}{|c|c|c|c|}
\hline \multirow[t]{2}{*}{ Item } & \multicolumn{3}{|c|}{$\begin{array}{l}\text { Nível de farelo de glúten de milho }(\%) \\
\text { Corn gluten meal level }\end{array}$} \\
\hline & 0 & 8 & 16 \\
\hline $\begin{array}{l}\text { Silagem de milho } \\
\text { Corn silage }\end{array}$ & 50,01 & 41,98 & 34,00 \\
\hline $\begin{array}{l}\text { FGM-21 } \\
\text { CGF-21 }\end{array}$ & 0,00 & 8,02 & 16,00 \\
\hline $\begin{array}{l}\text { Milho } \\
\text { Corn }\end{array}$ & 10,73 & 11,86 & 12,99 \\
\hline $\begin{array}{l}\text { Polpa cítrica } \\
\text { Citrus pulp }\end{array}$ & 10,73 & 11,86 & 12,99 \\
\hline $\begin{array}{l}\text { Farelo de algodão } \\
\text { Cottonseed meal }\end{array}$ & 25,00 & 23,02 & 21,01 \\
\hline $\begin{array}{l}\text { Uréia } \\
\text { Urea }\end{array}$ & 0,65 & 0,39 & 0,13 \\
\hline $\begin{array}{l}\text { Minerais e vitaminas } \\
\text { Mineral and vitamins }\end{array}$ & 2,18 & 2,18 & 2,18 \\
\hline $\begin{array}{l}\text { Bicarbonato de sódio } \\
\text { Sodium bicarbonate }\end{array}$ & 0,70 & 0,70 & 0,70 \\
\hline
\end{tabular}

${ }^{1}$ FGM-21: farelo de glúten de milho com 21\% PB (CGF-21: corn gluten feed with $21 \%(P)$.

2 Composição, kg (Composition, kg): Ca - 90 g; P - 20 g; S - 15g; Mg - 784 mg; Fe - 560 mg; Mn - 800 mg; Cu - 84 mg; Co - 50 mg; I 18 mg; Se - 29,2 mg; Zn - 111 mg; Na - 65 g; Fl - 18 mg; vit. A - 80.000Ul; vit. D - 21.000; vit. E - 500 IU.

Tabela 2 - Composição dos ingredientes das dietas experimentais (\%MS)

Table 2 - Composition of ingredients of experimental diets (\%DM)

\begin{tabular}{lrrrrc}
\hline Item & $\begin{array}{c}\text { Silagem } \\
\text { de milho } \\
\text { Corn } \\
\text { silage }\end{array}$ & $\begin{array}{c}\text { FGM-21 } \\
\text { CGF-21 }\end{array}$ & $\begin{array}{c}\text { Milho } \\
\text { Corn }\end{array}$ & $\begin{array}{c}\text { Polpa } \\
\text { cítrica } \\
\text { Citrus } \\
\text { pulp }\end{array}$ & $\begin{array}{c}\text { Farelo de } \\
\text { algodão } \\
\text { Cottonseed } \\
\text { meal }\end{array}$ \\
\hline PB, \% (CP) & 8,80 & 23,86 & 9,66 & 7,87 & 48,80 \\
FDN, \% (NDF) & 42,48 & 45,00 & 9,50 & 24,20 & 30,80 \\
CNF, \% (NFC) & 38,92 & 31,19 & 75,04 & 58,13 & 15,7 \\
FDA, \% (ADF) & 31,77 & 10,00 & 3,40 & 22,20 & 19,90 \\
EE, \% & 2,60 & 2,55 & 4,20 & 3,20 & 1,90 \\
Cinzas, \% (Ash) & 4,20 & 7,50 & 1,60 & 6,60 & 2,80
\end{tabular}

${ }^{1}$ FGM-21: farelo de glúten de milho com 21\% PB.

${ }^{1}$ CGF-21: corn gluten meal with $21 \%$ CP.
Tabela 3 - Composição química das dietas experimentais Table 3 - Chemical composition of the experimental diets

\begin{tabular}{lccr}
\hline Item & \multicolumn{3}{c}{ Nível de farelo de glúten de milho } \\
& \multicolumn{3}{c}{ Corn gluten meal level } \\
\cline { 2 - 4 } & 0 & 8 & 16 \\
\hline PB, \% CP & 18,6 & 18,38 & 17,88 \\
FDN, \% NDF & 37,85 & 38,93 & 38,47 \\
FDA, \% ADF & 25,81 & 23,92 & 23,52 \\
Cinzas, \% Ash & 7,58 & 6,99 & 6,64 \\
CNF, \% NFC & 33,73 & 33,39 & 34,86 \\
EE, \% & 2,24 & 2,31 & 2,15 \\
\hline
\end{tabular}

${ }^{1}$ FGM-21: farelo de glúten de milho com 21\% PB.

${ }^{1}$ CGF-21: corn gluten meal with $21 \% \mathrm{CP}$.

As vacas foram ordenhadas duas vezes ao dia, às 6 e $18 \mathrm{~h}$, pelo mesmo ordenhador, que utilizou solução pré-dipping e pós-dipping nos tetos de todos os animais e adotou o mesmo manejo para todos os grupos experimentais. As produções de leite individuais foram registradas nos três últimos dias de cada período experimental Amostras de leite de cada animal também foram coletadas duas vezes ao dia nos últimos três dias de cada período, conforme metodologia relatada por Acuri et al. (2004), e analisadas na Clínica do Leite - Esalq/USP quanto aos teores de gordura, proteína, lactose e sólidos totais, à contagem de células somáticas (CCS) e à concentração de N-uréico.

As produções de leite corrigidas para 3,5\% de gordura foram calculadas utilizando-se a equação proposta por Sklan et al. (1992):

Leite com $3,5 \%$ de gordura $=(0,432+0,1625 \times$ porcentagem de gordura) $\times \mathrm{kg}$ de leite

Amostras de sangue foram coletadas da veia coccígea em tubos de vidro com vácuo, contendo fluoreto de sódio e oxalato de potássio no último dia de cada período experimental, 4 horas após alimentação da manhã. As amostras foram centrifugadas a $4.000 \mathrm{rpm}$, durante 20 minutos; o plasma obtido foi acondicionado em tubos eppendorf e congelado a $-18^{\circ} \mathrm{C}$ para posterior determinação dos níveis de glicose utilizando-se o kit Sigma Trinder $505 \mathrm{~nm}$ (Sigma Diagnostics, St. Louis, MO). O nitrogênio uréico plasmático foi analisado de acordo com o método colorimétrico descrito por Chaney \& Marbach et al. (1962) e adaptado para leitura de absorbância utilizando-se placas de microtítulo e leitor de microplaca (Biorad, Hercules, CA, EUA).

A avaliação econômica das rações experimentais foi feita por meio de cotações de preços obtidos em sítios eletrônicos (IEA-CEPEA, 2006) e no Anualpec (2006). Os custos da produção de leite foram obtidos no Anualpec (2006) e os cálculos referentes à receita bruta e à renda líquida foram feitos conforme descrito por Hoffmann et al. (1984). 


\section{Resultados e Discussão}

A ingestão de MS observada nesta pesquisa $(22,22 \mathrm{~kg} /$ $\mathrm{vaca} / \mathrm{dia}$ ) foi semelhante à estimada pelo programa NRC (2001), de 22,9 kg/vaca/dia (Tabela 4).

Houve efeito significativo $(\mathrm{P}<0,001)$ dos níveis de FGM-21 na dieta sobre a produção de leite, que foi maior nos animais alimentados com as dietas contendo FGM-21. Esse resultado pode ser atribuído ao fornecimento de maior quantidade de fibra digestível e às condições mais favoráveis de fermentação ruminal, que possibilitaram melhor aproveitamento da dieta. Miron et al. (2004) utilizaram subprodutos fibrosos (casca de soja e farelo de glúten de milho) na dieta de vacas em lactação e também observaram aumento na produção de leite decorrente do melhor aproveitamento da dieta. Esses resultados confirmam os obtidos por Firkins et al. (1991), que substituíram a FDN da silagem de milho por FGM-21 (20\% da MS) e observaram aumento na produção de leite de 30,6 para $33,7 \mathrm{~kg} / \mathrm{dia}$ em vacas holandesas aos 140 dias de lactação.

Não houve efeito das dietas sobre as porcentagens de gordura, lactose, proteína e sólidos totais, no entanto, o rendimento em $\mathrm{kg}$ desses componentes foi maior $(\mathrm{P}<0,01)$ no leite dos animais alimentados com as dietas contendo FGM-21, em virtude de sua maior produção total de leite. Vanbaale et al. (2001) observaram maior produção de leite em animais alimentados com FGM-21 na MS (média de $41,6 \mathrm{~kg} / \mathrm{vaca} / \mathrm{dia}$ ) em comparação àqueles alimentados com a dieta sem FGM-21 (37,8 kg/vaca/dia).
Bernard et al. (1991), em estudo sobre a substituição de $27 \%$ da MS da silagem de milho por FGM-21 úmido e FGM-21 seco, não observaram diferença nas produções de leite e nas porcentagens de lactose e sólidos totais desengordurados, todavia, verificaram menor porcentagem de gordura no leite das vacas alimentadas com as dietas contendo FGM-21. Wickersham et al. (2004) também encontraram menores teores de gordura no leite de vacas alimentadas com FGM-21 úmido.

Neste estudo, nos níveis de substituição da FDN de 9,25\% em rações com 8\% de FGM-21 e de 18,7\% nas rações contendo $16 \%$ de FGM-21, não houve diferença na produção e nos teores de gordura no leite dos animais, o que comprova a efetividade da fibra do FGM-21. Zhu et al. (1997) estudaram o efeito da substituição de parte da FDN do volumoso da dieta de vacas em lactação por FDN de subprodutos e verificaram que nos animais alimentados com a dieta com $30 \%$ de FGM-21 seco, a média de produção de leite foi de $22,5 \mathrm{~kg} / \mathrm{vaca} / \mathrm{dia}$ com $3,0 \%$ de gordura e $3,6 \%$ de proteína e não diferiu da obtida com as outras dietas.

$\mathrm{Na}$ análise do $\mathrm{N}$-uréico do leite, apenas nos animais alimentados com a dieta contendo $16 \%$ de FGM-21, houve diminuição ( $\mathrm{P}=0,001)$ no $\mathrm{N}$-uréico do leite, que apresentou teor de PB ligeiramente mais baixo (Tabela 3 ), em virtude da correlação entre PB da dieta e N-uréico do leite (Wittwer et al., 1993; Roseler et al., 1993; Broderick \& Clayton, 1997; Jonker et al., 1998). Outros pesquisadores (Wickersham et al., 2004) estudaram o efeito da substituição de volumosos por $20 \%$ de FGM-21 úmido e encontraram média de

Tabela 4 - Produções de leite, gordura, proteína, lactose, sólidos totais e sólidos totais desengordurados, N-uréico no leite e contagem de células somáticas (CCS)

Table 4 - Milk yield, fat, protein, total solids, non-fat solids, $N$ ureic in milk and somatic cell count (SCC)

\begin{tabular}{|c|c|c|c|c|c|c|c|}
\hline \multirow[t]{2}{*}{ Item } & \multicolumn{6}{|c|}{$\begin{array}{l}\text { Nível de farelo de glúten de milho }{ }^{1}(\%) \\
\text { Corn gluten meal level }\end{array}$} & \multirow[t]{2}{*}{$P$} \\
\hline & 0 & $\begin{array}{c}\text { EPM } \\
\text { SEM }\end{array}$ & 8 & $\begin{array}{c}\text { EPM } \\
\text { SEM }\end{array}$ & 16 & $\begin{array}{c}\text { EPM } \\
\text { SEM }\end{array}$ & \\
\hline Leite (kg/anim.d) (Milk) & $22,44 b$ & 0,22 & $23,69 \mathrm{a}$ & 0,21 & $23,88 \mathrm{a}$ & 0,22 & $<0,001$ \\
\hline Leite $3,5 \%$ gord (kg/anim.d) (Fat milk $3.5 \%$ ) & $23,25 b$ & 0,40 & $24,71 \mathrm{a}$ & 0,39 & $24,44 \mathrm{ab}$ & 0,40 & 0,025 \\
\hline Gordura $(\%)($ Fat $)$ & 3,69 & 0,07 & 3,76 & 0,07 & 3,65 & 0,07 & 0,551 \\
\hline Gordura (kg/anim.d) (Fat) & 0,83 & 0,02 & 0,89 & 0,02 & 0,87 & 0,02 & 0,135 \\
\hline Proteína $(\%)$ (Protein) & 3,22 & 0,02 & 3,20 & 0,02 & 3,25 & 0,02 & 0,367 \\
\hline Proteína (kg/anim.d) (Protein) & $0,71 b$ & 0,01 & $0,75 \mathrm{a}$ & 0,009 & $0,76 \mathrm{a}$ & 0,01 & 0,002 \\
\hline Lactose $(\%)$ (Lactose) & 4,29 & 0,02 & 4,32 & 0,02 & 4,31 & 0,02 & 0,638 \\
\hline Lactose (kg/anim.d) (Lactose) & $0,97 \mathrm{~b}$ & 0,01 & $1,03 \mathrm{a}$ & 0,01 & $1,04 \mathrm{a}$ & 0,01 & $<0,001$ \\
\hline Sólidos totais (\%) (Total solids) & 12,12 & 0,09 & 12,23 & 0,089 & 12,14 & 0,09 & 0,663 \\
\hline Sólidos totais $(\mathrm{kg} / \mathrm{anim} / \mathrm{d})$ (Total solids) & $2,73 b$ & 0,03 & $2,90 \mathrm{a}$ & 0,03 & $2,89 \mathrm{a}$ & 0,03 & 0,0025 \\
\hline Solidos totais desengordurados (\%) (Total defatted solids) & 8,43 & - & 8,47 & - & 8,49 & - & - \\
\hline N-uréico no leite $(\mathrm{mg} / \mathrm{dL})$ (N ureic in milk) & $16,57 \mathrm{a}$ & 0,19 & $16,50 \mathrm{a}$ & 0,19 & $14,96 \mathrm{~b}$ & 0,19 & 0,001 \\
\hline $\log C C S(\log S C C)$ & $11,24 b$ & 0,11 & $11,25 b$ & 0,11 & $11,67 \mathrm{a}$ & 0,11 & 0,013 \\
\hline $\operatorname{CCS}(\mathrm{X} \mathrm{1000)*(SCC,x} 1000)$ & 660,81 & - & 676,05 & - & 748,14 & - & - \\
\hline
\end{tabular}

Médias na linha seguida de letras diferentes diferem $(P<0,05)$ pelo teste Tukey. Means within a row with different letters differ $(P<0.05)$ by Tukey test. 
$14,7 \mathrm{mg} / \mathrm{dL}$ de N-uréico no leite dos animais alimentados com a dieta contendo FGM-21, valor próximo ao encontrado no leite das vacas alimentadas com a dieta contendo $16 \%$ de FGM-21.

Apesar de o manejo higiênico pré e pós-ordenha ter sido idêntico em todos os lotes experimentais, observou-se aumento $(\mathrm{P}=0,013)$ da contagem de células somáticas no leite das vacas alimentadas com a dieta com 16\% de FGM- 21 . Todavia, a composição geral foi alta, fato que não está relacionado à dieta, e sim ao manejo adotado. Korhonen \& Kaartinen (1995) afirmaram que animais com CCS de 500.000 a 750.000, como neste estudo, apresentaram redução de 7\% da produção de leite.

Os resultados de CCS encontrados neste estudo foram similares aos descritos por Wickersham et al. (2004), que não notaram diferença na produtividade $(717.000 / \mathrm{mL}$ de CCS) de animais alimentados com 20\% de FGM-21 úmido em substituição à silagem de milho.

Os níveis plasmáticos de $\mathrm{N}$-uréico e glicose das vacas não foram influenciados pelas rações experimentais (Tabela 5). As médias de $\mathrm{N}$-uréico no plasma dos animais testados mantiveram-se acima de $19 \mathrm{mg} / \mathrm{dL}$. Alguns autores associam níveis de 19 a $20 \mathrm{md} / \mathrm{dL}$ de N-uréico plasmático a problemas reprodutivos (Butler,1996; Fergunson \& Chalupa, 1989), em decorrência do excesso de PB nas dietas experimentais, o que está de acordo com relatos de Hujens (1992) de que valores de $\mathrm{N}$-uréico no plasma superiores a $18 \mathrm{mg} / \mathrm{dL}$, juntamente com teores de proteína no leite acima de 3,2\%, podem ser interpretados, em vacas da raça Holandesa como excesso de proteína bruta, proteína degradável e proteína solúvel na dieta e como deficiência de carboidratos não-estruturais.

Vanbaale et al. (2001) encontraram, em vacas holandesas, valores de $\mathrm{N}$-uréico de 17,3 $4 \mathrm{mg} / \mathrm{dL}$ para animais controle e de $16,82 \mathrm{mg} / \mathrm{dL}$ para animais alimentados com FGM-21 em substituição ao volumoso, resultados inferiores aos encontrados neste estudo.

Os níveis séricos de glicose determinados neste estudo comprovam que os animais não se encontravam em déficits energéticos, pois, para manutenção dos processos fisiológicos normais, as vacas em lactação devem manter níveis de glicose sérica de 30 a $60 \mathrm{~mL} / \mathrm{dL}$, segundo Dukes \& Reece (1996), e de 45 a 75 mg/dL, segundo Kaneko et al. (1997).

Em vacas holandesas em lactação alimentadas com dietas contendo 0, 20, 27 e 35\% de FGM-21 em substituição à silagem de milho, Vanbaale et al. (2001) encontraram médias de glicose sérica de 67,7;68,8;68,3 e $68,9 \mathrm{mg} / \mathrm{dL}$, respectivamente, superiores às deste estudo. Valores mais próximos aos deste estudo foram relatados por Wickersham et al. (2004), que encontraram médias $61,2 \mathrm{mg} / \mathrm{dL}$ para vacas controle e de $60,9 \mathrm{mg} / \mathrm{dL}$ para vacas alimentadas com $20 \%$ de FGM-21 úmido, semelhança relacionada à similaridade entre as dietas utilizadas neste estudo por esses autores.

Os custos relativos dos alimentos devem ser considerados quando se pretende substituir um alimento por outro (Tabela 6). Para estimar o custo das dietas, foram multiplicados os custos das matérias-primas pelas suas proporções nas dietas experimentais, segundo o IEA-CEPEA (2006), obtendo-se o custo total por kg de MS em cada dieta.

Assim, o custo da FDN foi de R\$524,84/t para a silagem de milho e R \$549,31/t para FGM-21, próximo ao da polpa cítrica, cujo valor foi de $\mathrm{R} \$ 835,73 / \mathrm{t}$. No entanto, o custo relativo da $\mathrm{PB}$ é bastante elevado para silagem de milho, milho e polpa cítrica, ou seja, acima de $\mathrm{R} \$ 2.500,00 / \mathrm{t}$, enquanto, para o FGM-21, o valor de PB foi de R $\$ 1038,62 /$ t, mais próximo da principal fonte de $\mathrm{PB}$ das dietas, o farelo de algodão, que apresentou custo relativo da PB de $\mathrm{R} \$ 667,71 / \mathrm{t}$.

Aparentemente, os custos de cada dieta poderiam ser considerados iguais, tanto em custo $/ \mathrm{kg}$ de MS como em custo/vaca/dia (Tabela 6). Em razão da maior produção de leite, a receita bruta foi maior para a dieta contendo $16 \%$ de FGM-21, que mais lucrativa e com maior renda líquida. O custo da alimentação neste estudo foi em torno de $61,5 \%$ para todas as dietas e esteve de acordo com o descrito por Andrigueto et al. (2002), que estimou o custo da alimentação em $60 \%$ do custo total de produção.

Tabela 5 - Níveis de N-uréico e glicose plasmática

Table 5 - Means of levels of plasma $N$ ureic and glucose

\begin{tabular}{|c|c|c|c|c|c|c|c|}
\hline \multirow[t]{2}{*}{ Item } & \multicolumn{6}{|c|}{$\begin{array}{l}\text { Nível de farelo de glúten de milho }{ }^{1}(\%) \\
\text { Corn gluten meal level }\end{array}$} & \multirow[t]{2}{*}{$\mathrm{P}$} \\
\hline & 0 & $\begin{array}{c}\text { EPM } \\
\text { SEM }\end{array}$ & 8 & $\begin{array}{c}\text { EPM } \\
\text { SEM }\end{array}$ & 16 & $\begin{array}{c}\text { EPM } \\
\text { SEM }\end{array}$ & \\
\hline $\mathrm{N}$-uréico no plasma $(\mathrm{mg} / \mathrm{dL})$ (Plasma $N$ ureic) & 19,92 & 1,17 & 21,17 & 1,11 & 20,21 & 1,43 & 0,38 \\
\hline Glicose no plasma (mg/dL) (Plasma glucose) & 55,69 & 0,92 & 56,50 & 0,99 & 54,78 & 0,96 & 0,44 \\
\hline
\end{tabular}

${ }_{1}^{1}$ FGM-21: farelo de glúten de milho com 21\% PB.

${ }_{1}^{1}$ CGF-21: corn gluten meal with $21 \%$ CP. 
Tabela 6 - Cálculo dos custos de produção Table 6 - Calculation of production cost

\begin{tabular}{|c|c|c|c|}
\hline \multirow[t]{2}{*}{ Item } & \multicolumn{3}{|c|}{$\begin{array}{l}\text { Jível de farelo de glúten de milho (\%) } \\
\text { Corn gluten meal level }\end{array}$} \\
\hline & 0 & 8 & 16 \\
\hline $\begin{array}{l}\text { Custo/kg MS dieta }(\mathrm{R} \$) \\
\text { Costs/kg DM diet }\end{array}$ & 0,2637 & 0,2637 & 0,2640 \\
\hline $\begin{array}{l}\text { Consumo (kg MS/vaca/dia) } \\
\text { Intake (kg DM/cow/day) }\end{array}$ & 22,39 & 21,89 & 22,38 \\
\hline $\begin{array}{l}\text { Custo dos alimentos } \\
\text { (R\$/vaca/dia) }\end{array}$ & 5,8038 & 5,7928 & 5,8082 \\
\hline $\begin{array}{l}\text { Feed cost }(R \$ / \text { cow/day }) \\
\text { Outros custos }{ }^{1} \text { (R\$) } \\
\text { Other costs }{ }^{1}\end{array}$ & 3,6264 & 3,6264 & 3,6264 \\
\hline $\begin{array}{l}\text { Custo total }(\mathrm{R} \$) \\
\text { Total costs }(R \$)\end{array}$ & 9,4302 & 9,4192 & 9,4346 \\
\hline $\begin{array}{l}\text { Produção de leite }(\mathrm{kg} / \mathrm{vaca} / \mathrm{dia}) \\
\text { Milk yield }(\mathrm{kg} / \text { cow/day) }\end{array}$ & a) 22,44 & 23,69 & 23,88 \\
\hline $\begin{array}{l}\text { Valor do leite }(\mathrm{R} \$ / \mathrm{kg}) \\
\text { Milk value }\end{array}$ & 0,49 & 0,49 & 0,49 \\
\hline $\begin{array}{l}\text { Receita bruta } \\
\text { (venda do leite), R\$ } \\
\text { Gross marqin (market of milk) }\end{array}$ & 10,9956 & 11,6081 & 11,7012 \\
\hline $\begin{array}{l}\text { Renda líquida (R\$/vaca/dia) } \\
\text { Net income }(R \$ / \text { cow/day) }\end{array}$ & 1,5654 & 2,1889 & 2,2666 \\
\hline $\begin{array}{l}\text { Receita - custo com Net } \\
\text { alimentação (R\$) }\end{array}$ & 5,1918 & 5,8153 & 5,8930 \\
\hline $\begin{array}{l}\text { Feeding cost } \\
\% \text { custo alimento/custo total } \\
\% \text { Feeding cost/total costs }\end{array}$ & 61,54 & 61,50 & 61,56 \\
\hline $\begin{array}{l}\% \text { custo de alimentação/ } \\
\text { receita bruta } \% \\
\text { Feeding cost/gross margin }\end{array}$ & 52,78 & 49,90 & 49,64 \\
\hline
\end{tabular}

${ }^{1}$ Custos da produção de leite, sem incluir alimentação (Anualpec 2005)

${ }^{1}$ Costs of the milk production, without including feeding (Anualpec 2005).

$\mathrm{O}$ aumento da produção leiteira e a maior receita bruta resultaram em aumentos de $2,88 \%$ para a dieta com $8 \%$ de FGM-21 e de $3,14 \%$ para a dieta com $16 \%$ de FGM-21 na proporção custo da alimentação e receita bruta gerada pela venda do leite, o que gerou aumento da lucratividade.

\section{Conclusões}

A utilização de dietas contendo 8 e 16\% de FGM-21 em substituição a silagem de milho, na matéria seca, aumentou a produção de leite e as produções de proteína, sólidos totais e lactose do leite de vacas holandesas, sem modificar os teores dos componentes do leite. Os parâmetros metabólicos dos animais alimentados com dietas contendo FGM-21 foram iguais aos dos animais controle, sugerindo que o FGM-21 pode ser um alimento alternativo para vacas leiteiras. Os custos de produção das dietas foram similares, porém, o FGM-21 proporcionou maior margem líquida por litro de leite por dia.

\section{Literatura Citada}

ACURI, E.F.; SILVA, P.D.L; BRITO, J.R.F. et al. Emprego do somacount 300 , calibrado com leite de vaca, na contagem de células somáticas no leite de cabra. Ciência Rural, v.34, n.5, p.1497-1500, 2004.

ANDRIGUeTTO, J.M.; PERLY, L.; MINARDI, I. et al. Nutrição animal, as bases e os fundamentos da nutrição animal. Os alimentos. 5.ed. São Paulo: Nobel, 2002. v.1, 395p.

ANUAlPEC Anuário da Pecuária Brasileira. São Paulo: Instituto FNP Consultoria e Comércio, 2005. 340p.

ASSOCIATION OF OFFICIAL ANALYTICAL CHEMISTS - AOAC. Official methods of analysis. 12.ed. Washington, D.C.: 1990. $1180 \mathrm{p}$.

BERNARD, J.K.; DELOST, R.; MUELLER C.F.J. et al. Effect of wet or dry corn gluten feed on nutrient digestibility and milk yield and composition. Journal of Dairy Science, v.74, n.11, p.3913-3919, 1991

BRODERICK, G.A.; CLAYTON, M.K. A statistical evaluation of animal and nutritional factors influencing concentrations of milk urea nitrogen. Journal of Dairy Science, v.80, n.11, p.2964-2971, 1997.

BUTLER, W.R. Symposium: optimizing protein nutrition for reproduction and lactation. Journal of Dairy Science, v.81, n.9, p.2533-2539, 1996.

CEPEA [2005]. Centros de estudos avançados em economia aplicada - Esalq/USP. Boletim do leite. Disponível em: <www.cepea.esalq.usp.br.> Acesso em: 25/4/2006.

CHANEY, A.L.; MARBACH, E.P. Modified reagents for determination of urea and amonia. Clinical Chemistry, v. 8 , p.130-132, 1962 .

DUKES, H.H; REECE W. Physiology of domestic animals. Rio de Janeiro: Guanabara, 1996. 999p.

DUTRA, A.R.; QUEIROZ, A.C.; PEREIRA, J.C. et al. Efeitos dos níveis de fibra e das fontes de proteínas sobre a síntese de compostos nitrogenados microbianos em novilhos. Revista Brasileira de Zootecnia, v.26, n.4, p.797-805, 1997.

FERGUNSON, J.D.; CHALUPA, R. Symposium: interactions of nutrition and reproduction. Journal of Dairy Science, v.73, n.3, p.746-766, 1989.

FIRKINS, J.L; EASTRIDGE, M.L; PALQUIST, D.L. Replacement of corn silage with corn gluten feed and sodium bicarbonate for lactating dairy cows. Journal of Dairy Science, v.74, n.6, p.1944-1952, 1991.

GONZÁLEZ, F.H.D. Uso do perfil metabólico para determinar o status nutricional em gado de corte. In: GONZÁLEZ, F.H.D.; BARCELlos, J.; PATIÑO, H.O. et al. (Eds.) Perfil metabólico em ruminantes: seu uso em nutrição e doenças nutricionais Porto Alegre: Universidade Federal do Rio Grande do Sul, 2000. p.63-74.

GRANT, R. Optimizing starch concentrations in dairy rations Fort Wayne: W. H. Miner Agricultural Research Institute TriState Dairy Nutrition Conference, Grand Wayne Center, 2005. p.73-79.

HARRIS, L.E. Nutrition research technique for domestic and wild animal. Gainesville: University of Florida, 1970. 150p.

HOFFMANN, R.; SERRANO, O.; NEVES, E.M. et al. Administração da empresa agrícola. 4.ed.rev. São Paulo: Pioneira, 1984. $325 \mathrm{p}$.

HUJENS, M.F. Selecting feed additives. In: VANHORN, H.H.; WILCOX, C.J. (Eds.) Large dairy herd management. Champaign: American Dairy Science Association, 1992. p.309-317.

IMAIZUMI, H. Suplementação protéica, uso de subprodutos agroindustriais e processamento de milho em dietas para vacas leiteiras em confinamento. Piracicaba: Escola Superior de Agricultura Luiz de Queiroz. Universidade, 2005. 90p. Tese (Doutorado em Ciência Animal) - Escola Superior de Agricultura Luiz de Queiroz, 2005. 
INSTITUTO DE ECOMOMIA AGRÍCOLA [2006a]. Preços médios pagos pela agricultura. Disponível em: <www.iea.sp.gov.br/ out/banco/menu.php> Acesso em: 25/4/2006.

INSTITUTO DE ECOMOMIA AGRÍCOLA [2006b]. Preços médios recebidos pelos agricultores. Disponível em: $<$ www.iea.sp.gov.br/out/banco/menu.php> Acesso em: 25/4/2006.

JONKER, J.S.; KOHN, R.A.; ERDMAN, R.A. Using milk urea nitrogen to predict nitrogen excretion and utilization efficiency in lactating dairy cows. Journal of Dairy Science, v.81, n.10, p.2681-2692, 1998.

KANEKO, J.J.; HARVEY, J.W.; BRUSS, M.L. Clinical biochemistry of domestic animals. 5.ed. San Diego: Academic Press, 1997. $890 \mathrm{p}$.

MIRON, J.; YOSEF, E.; ZENOU, A. et al. Feeding behavior and performance of dairy cows fed pelleted nonroughage fiber byproducts. Journal of Dairy Science, v.87, n.5, p.13721379,2004

MONACO, G.M. Vantagens de investir na qualidade do leite. São Paulo: Instituto FNP, 2005. p.169-170.

NATIONAL RESEARCH COUNCIL - NRC. Nutrient requirements of beef cattle. 7.ed. Washington: National Academy of Science, 2001. 248p

REIS, R.A.; ANDRADE, P.; ROSA, B. et al. Efeito da suplementação protéica sobre o valor nutritivo da palha de aveia preta tratada com amônia. Revista Brasileira de Zootecnia, v.24, n.2, p.223-232, 1995.

ROSELER, D.K.; FERGUNSON, J.D.; SNIFFEN, C.J. et al. Dietary protein degradability effects on plasma and milk urea nitrogen and milk nonprotein nitrogen in Holstein cows. Journal of Dairy Science, v.76, n.2, p.525-534, 1993.

SANTOS, F.A.P.; CARMO, C.A.; MARTINEZ, J.C. et al. Desempenho de vacas em lactação recebendo dietas com diferentes teores de amido total, acrescidas ou não de levedura (Saccharomyces cerevisiae). Revista Brasileira Zootecnia, v.35, n.4, p.1568-1575, 2006.

STATISTICAL ANALYSIS SYSTEM - SAS. SAS user's guide: statistics. version 9.1. 6.ed. Cary: 2003. (CD-ROM).
SKLAN, D.R.; ASHKENAZI, A.; BRAUN, A. et al. Fatty acids, calcium soaps of fatty acids, and cottonseeds fed to high yielding cows. Journal of Dairy Science, v.75, n.9, p.2463-2472, 1992.

SOUZA, O.E.; SANTOS, E.I. [2004]. Aproveitamento de resíduos e subprodutos agropecuários pelos ruminantes na Embrapa Disponível em: <www.cpatc.embrapa.br/index.php?idpagina= artigos\&artigo $=914>$. Acesso em: 11/1/2006.

Van SOEST, P.J.; ROBERTSON, J.B.; LEWIS, B.A. Methods for dietary fiber, neutral detergent fiber, and no starch polysaccharides in relation to animal nutrition. Journal of Dairy Science, v.74, n.10, p.3583-3597, 1991 .

VANBAALE, M.J.; SHIRLEY, J.E.; TITGEMEYER, E.C. et al Evaluation of wet corn gluten feed in diets for lactating dairy cows. Journal of Dairy Science, v.84, n.11, p.2478-2485, 2001.

WICKERSHAM, E.E.; SHIRLEY, J.E..; BROUK, M.J. et al., Response of lactating dairy cows to diets containing wet corn gluten feed or raw soybean hull-corn steep liquor pellet. Journal of Dairy Science, v.87, n.11, p.3899-3911, 2004.

WILDMAN, E.E.; JONES, G.M.; WAGNER, P.E. et al. A dairy condition scoring system and its relationship to selected production characteristics. Journal of Dairy Science, v.65, n.3, p.495-498, 1982.

WITTWER, F.; REYES, J.M.; OPITZ, H. et al. Determinación de urea en muestras de leche de rebaños bovinos para el diagnóstico de desbalance nutricional. Archivos de Medicina Veterinaria, v. 25, n.2, p.165-172, 1993.

ZHU, J.S.; STOKES, S.R.; MURPHY, M.R. Substitution of neutral detergent fiber from forage with neutral detergent fiber from by-Products in the diets of lactating cows Journal of Dairy Science, v.80, n.11, p.2901-2906, 1997 